\title{
National study of continuity clinic satisfaction in pediatric fellowship training
}

This article was published in the following Dove Press journal:

Advances in Medical Education and Practice

13 September 2013

Number of times this article has been viewed

\author{
Mariam Gangat' \\ Genna W Klein' \\ Hillel W Cohen ${ }^{2}$ \\ Rubina A Heptulla' \\ 'Division of Pediatric Endocrinology \\ and Diabetes, The Children's Hospital \\ at Montefiore, ${ }^{2}$ Department of \\ Epidemiology and Population Health, \\ Albert Einstein College of Medicine, \\ Bronx, New York, NY, USA
}

Background: A national online survey was conducted to evaluate pediatric subspecialty fellow satisfaction regarding continuity clinic experience.

Methods: An anonymous online survey (SurveyMonkey ${ }^{\mathrm{TM}}$ ) was developed to evaluate demographics of the program, clinic organization, and patient and preceptor characteristics, and to compare fellow satisfaction when fellows were the primary providers with faculty supervision versus attending-run clinics assisted by fellows or a combination of the two models. Pediatric subspecialty fellows in a 3-year Accreditation Council for Graduate Medical Education accredited program in the United States (excluding emergency medicine, neonatology, and critical care) were invited to participate.

Results: There were 644 respondents and nearly half (54\%) of these had fellow-run clinics. Eighty-six percent of fellows responded that they would prefer to have their own continuity clinics. Higher satisfaction ratings on maintaining continuity of care, being perceived as the primary provider, and feeling that they had greater autonomy in patient management were associated with being part of a fellow-run clinic experience (all $P<0.001$ ). Additionally, fellow-run clinics were associated with a feeling of increased involvement in designing a treatment plan based on their differential diagnosis $(P<0.001)$. There were no significant associations with patient or preceptor characteristics.

Conclusion: Fellow-run continuity clinics provide fellows with a greater sense of satisfaction and independence in management plans.

Keywords: resident education/training, workforce, pediatric, patient-provider relationship, pediatric outpatient clinic

\section{Introduction}

Continuity of care is defined as care of a patient as documented by recurring visits between the same patient and care provider over time. This model of care allows for development of mutual respect between the physician and patient, resulting in effective and efficient health care over time. ${ }^{1}$ With an increasing shift in health care to the outpatient setting, ${ }^{2}$ structured continuity experience requiring pediatric residents to attend a continuity clinic one half-day per week became a mandatory part of pediatric residency training. Prior to these requirements from the Accreditation Council for Graduate Medical Education (ACGME), some programs had continuity clinics scheduled on a weekly or biweekly basis. ${ }^{1}$ Although the ACGME has specific requirements for continuity clinics in pediatric residency training, ${ }^{3}$ requirements for subspecialties are less stringent, allowing for increased flexibility in structure and implementation.
Correspondence: Rubina A Heptulla The Children's Hospital at Montefiore, Division of Pediatric Endocrinology and Diabetes, 34I I Wayne Avenue, Fourth Floor, Bronx, New York, NY I0467, USA

Tel + I 7189205473

$\mathrm{Fax}+\mathrm{I} 7184055609$

Email rubina.heptulla@einstein.yu.edu 
Few published studies have evaluated the continuity clinic experience in pediatric residency training ${ }^{1,2,4,5}$ and a recent study evaluated the satisfaction of pediatric infectious diseases fellows. ${ }^{6}$ To our knowledge, this is the first study evaluating the outpatient clinic experience across all pediatric subspecialties. We aimed to determine the proportion of respondents in a national survey of pediatric subspecialty fellows who participated in fellow-run clinics, and to compare fellow satisfaction between fellow-run and attending-run clinics.

\section{Materials and methods}

We developed an anonymous online survey through SurveyMonkey ${ }^{\mathrm{TM}}$ assessing the following: demographics of the program; clinic organization; autonomy in patient management; being perceived as a primary provider; continuity of care; patient characteristics; preceptor characteristics; and teaching (Table 1). Responses utilized Likert scale ratings (1, disagree strongly; 2 , disagree; 3 , neutral; 4, agree; 5, agree strongly). The survey was distributed via email to program directors of all 3-year ACGME-accredited pediatric fellowship programs in the United States. We excluded emergency

Table I Select survey questions

\begin{tabular}{l} 
Which of the following best describes your primary outpatient \\
continuity clinic? \\
Fellow-run clinic: fellow is the primary provider with own patient \\
panel and is supervised by attending(s) \\
Attending-run clinic: attending is the primary provider, fellow sees \\
some of the attending panel and is supervised by the attending \\
Both \\
Other (please specify) \\
The way my clinic is organized promotes continuity of care \\
The patients I see consider me their primary provider \\
I have autonomy in patient management \\
Patient characteristics \\
The patients I see in clinic have a broad range of socioeconomic \\
backgrounds \\
The patients I see in clinic have an adequate diversity of medical \\
conditions \\
The patients I see in clinic have an adequate level of complexity of \\
medical conditions \\
Preceptor characteristics \\
The supervising attending(s) are easily accessible in between clinics \\
I receive an appropriate amount of feedback from my supervising \\
attending(s) \\
The teaching I receive in clinic has improved my skills in \\
History-taking \\
Performing a physical examination \\
Formulating a differential diagnosis \\
Selecting appropriate diagnostic test(s) \\
Interpreting diagnostic test(s) \\
Developing a treatment plan \\
\hline
\end{tabular}

medicine, neonatology, and critical care programs because fellows have limited or no outpatient clinics. The email asked program directors to forward the survey to their fellows. Survey responses were tabulated electronically by the website software. As an incentive to participate, respondents were entered into a chance to win a 100 dollar gift card at the completion of the survey. The institutional review board at The Albert Einstein College of Medicine approved the study protocol.

\section{Statistical methods}

Clinic type was considered an ordered variable based on the proportion of clinics that were fellow-run, with all fellowrun clinics coded as 3, both fellow and attending-run clinics coded as 2, and all attending-run clinics coded as 1 . The number of clinics was dichotomized as 1 or more than 1 . Survey questions with five-point Likert scales were dichotomized into agree and not agree, with responses 4 and 5 (agree and agree strongly) considered as agree compared with the combination of neutral, disagree, and disagree strongly. The proportions of those who agreed with the survey questions were calculated and tested for association with clinic type using a Mantel-Haenszel linear-by-linear chi-square test for trend. In addition, binary logistic regression models were constructed to estimate the association (reported as odds ratios and $95 \%$ confidence intervals) of the ordered clinic type as independent variable with agreement for continuity of care, primary provider, autonomy, and overall satisfaction as the binary outcome variable while simultaneously adjusting for the number of clinics and teaching questions that showed bivariate associations with clinic type. Logistic models were checked with the Hosmer-Lemeshow statistic for goodness of fit. A $P$-value $\leq 0.05$ was used to denote statistical significance. Statistical analyses were performed using Statistical Package for the Social Sciences version 19 (SPSS Inc., Chicago, IL, USA) and 20 software (IBM, Armonk, NY, USA).

\section{Results}

Of 2,272 possible respondents, we received 644 responses, yielding a response rate of $28 \%$. The highest response rates were from hematology/oncology $(n=133 / 20.7 \%)$, followed by cardiology $(n=115 / 17.9 \%)$, endocrinology $(n=97 / 15.1 \%)$, infectious diseases $(n=75 / 11.6 \%)$, pulmonology $(n=62 / 9.6 \%)$, gastroenterology $(n=61 / 9.5 \%)$, developmental-behavioral $(n=32 / 5 \%)$, nephrology $(n=31 / 4.8 \%)$, adolescent medicine $(n=21 / 3.3 \%)$, and rheumatology $(n=17 / 2.6 \%)$. There was a similar percentage of respondents in terms of level of training; 
postgraduate year $4(\mathrm{n}=194 / 30.1 \%)$, postgraduate year 5 $(n=233 / 36.2 \%)$, and postgraduate year $6(n=217 / 33.7)$. Three hundred and forty-seven (53.9\%) respondents had fellow-run clinics, 136 (21.1\%) had attending-run clinics, and the remaining $161(25 \%)$ had a combination of both. The majority of respondents $(n=555 / 86.2 \%)$ said that, if given an option, they would choose fellow-run clinics.

Table 2 shows the proportions of reporting agreement with autonomy, primary provider, continuity of care, and overall satisfaction as well as patient characteristics, preceptor characteristics, and teaching experiences. Patient and preceptor characteristics did not vary significantly by clinic type, whereas clinic type showed strongly significant linear associations with reported agreement for autonomy, primary provider, continuity of care, and overall satisfaction. Among the aspects of teaching experience, formulating a differential diagnosis, interpreting tests, and developing a treatment plan were significantly associated with clinic type, while selecting tests had a borderline significant association with clinic type. History-taking and physical examination were not significantly associated with clinic type.

Table 3 shows odds ratios and 95\% confidence intervals for the several outcome variables while simultaneously

Table 2 Responses of fellows regarding administered survey

\begin{tabular}{|c|c|c|c|c|}
\hline & $\begin{array}{l}\text { Fellow- } \\
\text { run clinic } \\
n=347\end{array}$ & $\begin{array}{l}\text { Both } \\
n=136\end{array}$ & $\begin{array}{l}\text { Attending- } \\
\text { run clinic } \\
n=16 \mid\end{array}$ & $\begin{array}{l}P \text { for } \\
\text { trend }\end{array}$ \\
\hline Autonomy & $85 \%$ & $19 \%$ & $14 \%$ & $<0.001$ \\
\hline Primary provider & $91 \%$ & $58 \%$ & I I\% & $<0.001$ \\
\hline Continuity of care & $90 \%$ & $71 \%$ & $46 \%$ & $<0.001$ \\
\hline \multicolumn{5}{|l|}{ Patient characteristics } \\
\hline Complexity & $91 \%$ & $90 \%$ & $93 \%$ & $0.7, \mathrm{NS}$ \\
\hline Diversity & $86 \%$ & $86 \%$ & $88 \%$ & $0.7, \mathrm{NS}$ \\
\hline $\begin{array}{l}\text { Socioeconomic } \\
\text { background }\end{array}$ & $83 \%$ & $85 \%$ & $89 \%$ & $0.1, \mathrm{NS}$ \\
\hline \multicolumn{5}{|c|}{ Preceptor characteristics } \\
\hline Accessibility & $90 \%$ & $89 \%$ & $94 \%$ & $0.22, \mathrm{NS}$ \\
\hline Feedback & $79 \%$ & $70 \%$ & $77 \%$ & $0.47, \mathrm{NS}$ \\
\hline \multicolumn{5}{|l|}{ Teaching } \\
\hline History-taking & $78 \%$ & $75 \%$ & $75 \%$ & $0.45, \mathrm{NS}$ \\
\hline $\begin{array}{l}\text { Physical } \\
\text { examination }\end{array}$ & $68 \%$ & $63 \%$ & $70 \%$ & $0.69, \mathrm{NS}$ \\
\hline $\begin{array}{l}\text { Formulating } \\
\text { differential } \\
\text { diagnosis }\end{array}$ & $96 \%$ & $90 \%$ & $88 \%$ & 0.001 \\
\hline Selecting tests & $97 \%$ & $92 \%$ & $93 \%$ & $0.068, N S$ \\
\hline Interpreting tests & $95 \%$ & $92 \%$ & $89 \%$ & 0.006 \\
\hline Treatment plan & $98 \%$ & $95 \%$ & $91 \%$ & $<0.001$ \\
\hline Overall satisfaction & $89 \%$ & $83 \%$ & $75 \%$ & $<0.001$ \\
\hline $\begin{array}{l}\text { Number of clinics } \\
(I \text { versus }>I)\end{array}$ & $82 \%$ & $60 \%$ & $69 \%$ & $<0.001$ \\
\hline
\end{tabular}

Abbreviation: NS, not statistically significant.
Table 3 Association of outcomes with clinic type expressed as odds ratio per category of increasing fellow-run clinics

\begin{tabular}{lll}
\hline Outcome & Odds ratio $(95 \% \mathrm{Cl}) *$ & P-value \\
\hline Continuity of care & $3.2(2.5-4.0)$ & $<0.001$ \\
Autonomy & $3.0(2.4-3.8)$ & $<0.001$ \\
Primary provider & $9.0(6.6-12.3)$ & $<0.001$ \\
Overall satisfaction & $1.4(1.1-1.9)$ & 0.010 \\
\hline
\end{tabular}

Notes: *From binary logistic models for agreement while simultaneously adjusting for having one clinic and agreement with the following teaching characteristics: treatment plan, interpreting test, selecting test, and differential diagnosis. Abbreviation: $\mathrm{Cl}$, confidence interval.

adjusting for having one clinic and agreement with the following teaching characteristics: formulating differential diagnosis, selecting tests, interpreting tests, and treatment plan. Each of the four outcome variables was significantly associated with clinic type even after adjustment for the number of clinics and teaching experience.

\section{Discussion}

Given the minimal guidelines as to the structure of continuity clinics in pediatric fellowship training, there can be great variability in design and implementation. We found that more than half of respondents (54\%) had fellow-run clinics. The majority of fellows (86\%) stated that they would choose fellow-run clinics if given an option.

Among the most important findings of this study are that higher satisfaction ratings on measures of continuity of care, being perceived as the primary provider, and autonomy in decision-making were associated with fellowrun clinics. Continuity of care is a critical component of the outpatient clinic experience, both for fellow education and patient care. ${ }^{1}$ Continuity of care has been shown to improve patient satisfaction as well as adherence with medication and appointments. ${ }^{7,8}$ A survey of over 700 patients found a significant association between continuity of care and overall satisfaction with care. The authors suggested that consistent contact leads to mutual knowledge, and visits in the setting of mutual knowledge may be more efficient and rewarding. ${ }^{9}$ Further, the financial benefits of continuity have also been described, with reduced hospitalization rates and number of laboratory tests performed. ${ }^{10}$

In evaluating the teaching experience, no differences were seen between the three different clinic structure categories in improving history-taking and physical examination skills. This is not surprising because these are basic skills taught in medical school and residency, leading to confidence in these areas by fellowship training. However, respondents with fellow-run clinics were more likely to report that their 
clinic organization improved their skills in more advanced aspects of patient care, including formulating a differential diagnosis, selecting the appropriate diagnostic test(s), interpreting results, and formulating a treatment plan. The development of these skills can often be overlooked in an attending-run clinic, given that clinics are often very busy and limited by time constraints. However, being skilled in these areas is vital to the growth and maturation of a fellow into a confident and efficient attending physician.

There is increasing demand for specialized, diseasespecific care in pediatrics. Data from several children's hospitals show increasing numbers of referrals to pediatric subspecialists. ${ }^{11}$ To meet this gap, fellowship training must be structured to prepare fellows for providing high-quality health care and successful academic careers. Although restructuring can meet resistance from those who support the "current way" and can face challenges such as faculty time and financial constraints, it is imperative that continuity clinics are organized to optimize the education of fellows and improve patient care. Innovative models to transform continuity clinics have been described, and a recent study presented the benefits of a resident-driven council empowering residents to implement system changes. ${ }^{12}$

There are some limitations to this study. First, we were unable to determine an accurate response rate because participation in the survey was contingent on fellowship program directors forwarding the survey to their fellows. Thus, we do not know to what extent our sample is representative of the population of subspecialty fellows. However, the sample size is large and includes fellows from all specialties and all levels of training across the nation. Second, the data are based on subjective perceptions by fellows, not objective measurements. Also, possible confounders such as patient population and patient turnover, were not evaluated. Despite these limitations, we believe the data from this study provide meaningful information on optimizing the outpatient fellowship clinic experience. Further studies in this area investigating objective measures of continuity of care as well as preceptor and patient perspectives are needed.

\section{Conclusion}

The structure of continuity clinics in fellowship should promote essential components of training, such as continuity of care and autonomy in decision-making. These components are critical for both fellow education as well as patient care. Data from this study suggest that fellow-run clinics are more likely to promote these components.

\section{Author contributions}

MG conceptualized and designed the study, executed the survey, drafted the initial manuscript, and approved the final manuscript as submitted. GWK designed the study, reviewed and revised the manuscript, and approved the final manuscript as submitted. HWC designed the data collection instruments, did the statistical analysis, wrote the statistical portion of the manuscript, and approved the final manuscript as submitted. RAH conceptualized and designed the study, critically reviewed and revised the manuscript, and submitted the final manuscript to the journal.

\section{Disclosure}

The authors report no conflicts of interest in this work.

\section{References}

1. Garfunkel LC, Byrd RS, McConnochie KM, Auinger P. Resident and family continuity in pediatric continuity clinic: nine years of observation. Pediatrics. 1998;101:37-42.

2. Dumont-Driscoll MC, Barbian LT, Pollock BH. Pediatric residents' continuity clinics: how are we really doing? Pediatrics. 1995;96: 616-621.

3. Copeland KC, Silverstein J, Moore KR, et al. Management of newly diagnosed type 2 diabetes mellitus (T2DM) in children and adolescents. Pediatrics. 2013;131:364-382.

4. Serwint JR. Multisite survey of pediatric residents' continuity experiences: their perceptions of the clinical and educational opportunities. Pediatrics. 2001;107:E78.

5. Barratt MS, Tanz RR. A survey of the structure and function of pediatric continuity clinics. Am J Dis Child. 1992;146:937-940.

6. Douvoyiannis M, Litman N, Belamarich PF, Goldman DL. A survey of current and past pediatric infectious diseases fellows regarding training. BMC Med Educ. 2011;11:72.

7. Dietrich AJ, Marton KI. Does continuous care from a physician make a difference? J Fam Pract. 1982;15:929-937.

8. Alpert JJ. Broken appointments. Pediatrics. 1964;34:127-132.

9. Christakis DA, Wright JA, Zimmerman FJ, Bassett AL, Connell FA. Continuity of care is associated with high-quality careby parental report. Pediatrics. 2002;109:e54.

10. Heagarty MC, Robertson LS, Kosa J, Alpert JJ. Some comparative costs in comprehensive versus fragmented pediatric care. Pediatrics. 1970;46:596-603.

11. Boat TF. Evolution of subspecialty care in pediatrics. $J$ Pediatr. 2002;140:639-640.

12. Colbert CY, Myers JD, Cable CT, et al. An alternative practice model: residents transform continuity clinic and become systems thinkers. J Grad Med Educ. 2012;4:232-236. 
Advances in Medical Education and Practice

Dovepress

\section{Publish your work in this journal}

Advances in Medical Education and Practice is an international, peerreviewed, open access journal that aims to present and publish research on Medical Education covering medical, dental, nursing and allied health care professional education. The journal covers undergraduate education, postgraduate training and continuing medical education including emerging trends and innovative models linking education, research, and health care services. The manuscript management system is completely online and includes a very quick and fair peer-review system. Visit http://www.dovepress.com/testimonials.php to read real quotes from published authors.

Submit your manuscript here: http://www.dovepress.com/advances-in-medical-education-and-practice-journal 